\title{
Retraction
}

\section{Author-Initiated Retraction: Warne et al, Coordinated Regulation of Hepatic Energy Stores by Leptin and Hypothalamic Agouti-Related Protein}

At the request of the authors, The Journal of Neuroscience is retracting "Coordinated Regulation of Hepatic Energy Stores by Leptin and Hypothalamic Agouti-Related Protein” by James P. Warne, Jillian M. Varonin, Sofie S. Nielsen, Louise E. Olofsson, Christopher B. Kaelin, Streamson Chua, Jr., Gregory S. Barsh, Suneil K. Koliwad, and Allison W. Xu, which appeared on pages 11972-11985 of the July 17,2013 issue.

DOI:10.1523/JNEUROSCI.3728-14.2014 